\title{
Capillary Blood
}

National Cancer Institute

\section{Source}

National Cancer Institute. Capillary Blood. NCI Thesaurus. Code C112235.

A mixture of arterial blood, venous blood and interstitial fluid, which is found in the capillaries. 